\title{
Снижение помех в синхронных понижающих преобразователях с помощью дополнительного диода Шоттки на примере ADP2443 от компании Analog Devices
}

\author{
$\Phi$. Досталь $^{1}$
}

УДК 621.314.1| ВАК 05.27.01

\begin{abstract}
Для построения локализованных к нагрузке понижающих преобразователей широко применяют синхронные схемы, содержащие активные ключи верхнего и нижнего плеча. Импульсные стабилизаторы выгодно отличаются от схем, в которых в качестве ключа нижнего плеча используется пассивный диод Шоттки. Основное их преимущество - более высокая эффективность преобразования напряжения вследствие меньшего падения напряжения , возникающего когда ключ нижнего плеча проводит ток. Однако по сравнению с асинхронными импульсными стабилизаторами синхронные преобразователи могут стать причиной более высокого уровня помех в схеме. В статье описан способ минимизации этих помех.
\end{abstract}

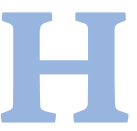

а рис. 1 показана схема понижающего преобразователя на основе синхронного импульсного стабилизатора с идеальными ключами. Когда оба ключа закрываются одновременно, даже на короткий период времени, возникает короткозамкнутая цепь между входным напряжением и землей, что может вывести ключи из строя. Необходимо обеспечить, чтобы два ключа никогда не включались одновременно. Из соображений безопасности нужно предусмотреть определенный период времени, в течение которого оба ключа находятся в выключенном состоянии, - время паузы.

Однако следует отметить, что ток через катушку индуктивности L1 (см. рис. 1), которая соединяет коммутационный узел (общую точку ключей) с выходным напряжением, нельзя изменить мгновенно. Он увеличивается или уменьшается плавно, а не скачкообразно. Таким образом, во время паузы включения ключей могут возникнуть проблемы. Все пути тока прерываются на коммутационном узле схемы. В случае идеальных ключей, как показано на рис. 1, во время паузы на коммутационном узле появляется бесконечное отрицательное напряжение. В ситуации с реальными ключами это отрицательное напряжение увеличивается до тех пор, пока не произойдет пробой одного из ключей, и он не начнет пропускать ток.

В большей части импульсных стабилизаторов в качестве активных ключей используются п-канальные MOSFET. Такие устройства отличаются полезным для применения

Компания Analog Devices, специалист по компонентам для систем управления питанием, frederik.dostal@analog.com в подобных схемах свойством - так называемым встроенным диодом (body diode), который представляет собой p-n-переход между истоком и стоком транзистора. На рис. 2 показано, как включены MOSFET в качестве активных ключей в схеме импульсного стабилизатора. В такой схеме напряжение на коммутационном узле не снижается до бесконечности даже во время паузы между включением ключей, вместо этого p-n-переход в MOSFET нижнего плеча (показан на схеме красным цветом) будет проводить ток до тех пор, пока не завершится пауза и не включится MOSFET нижнего плеча.

Однако встроенные диоды в MOSFET обладают серьезным недостатком. Из-за эффекта обратного восстановления они характеризуются очень низкой скоростью переключения. Во время обратного восстановления

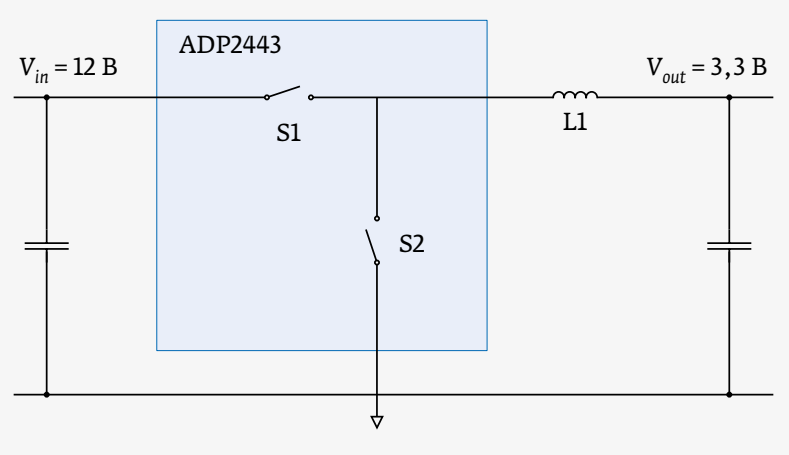

Рис. 1. Синхронный импульсный стабилизатор в схеме понижающего преобразователя с идеальными ключами 
напряжение на коммутационном узле падает до нескольких вольт ниже уровня земли благодаря катушке Ll. Taкие резкие скачки напряжения приводят к помехам, которые из-за емкостной связи могут наводиться на другие участки схемы. Помехи можно минимизировать путем включения дополнительного диода Шоттки, как показано на рис. 2. В отличие от встроенного диода в MOSFET нижнего плеча, этому диоду не требуется время для обратного восстановления. В паузе между включением MOSFET OH сразу же начинает пропускать ток. Это обеспечивает намного меньший перепад напряжения в коммутационном узле. Как следствие, генерируется и распространяется по схеме гораздо меньше помех.

Диод Шоттки очень компактен, поскольку проводит ток только в короткие периоды пауз, сильно не нагревается и его можно поместить в небольшой и недорогой корпус.

ADP2443 - синхронный понижающий стабилизатор постоянного напряжения с интегрированными MOSFET верхнего и нижнего плеча, обеспечивающий высокий КПД в компактном корпусе LFCSP (4×4 мм). Стабилизатор работает с входным напряжением в диапазоне от 4,5 до 36 В. Минимальное регулируемое выходное напряжение составляет 0,6 В, выходной ток достигает 3 А в непрерывном режиме. Благодаря малому минимальному времени включенного состояния (50 нс) ADP2443 способен выполнять преобразование высокого входного напряжения в низкое выходное напряжение на высокой частоте.

Для достижения высокой стабильности и обеспечения быстрой переходной характеристики в ADP2443 применена схема управления на основе эмуляции токового режима с ШиМ-сигналами постоянной частоты. Частота коммутации ADP2443 может программироваться пользователем в диапазоне от 200 кГц до 1,8 МГц. Имеется возможность синхронизировать частоту коммутации устройства с внешним тактовым сигналом для минимизации шумов в системе.

ADP2443 предназначен для высококачественных приложений, где требуются высокий КПД и гибкость проектного решения, которая достигается благодаря применению внешней компенсации и функции регулируемого мягкого запуска. Выход "питание в норме» и вход разрешения с прецизионным порогом позволяют реализовать простую и надежную процедуру включения / отключения питания.

К другим важнейшим функциям устройства относятся блокировка при просадке напряжения, защита от перегрузки по напряжению и по току, защита от короткого замыкания и отключение при перегреве.

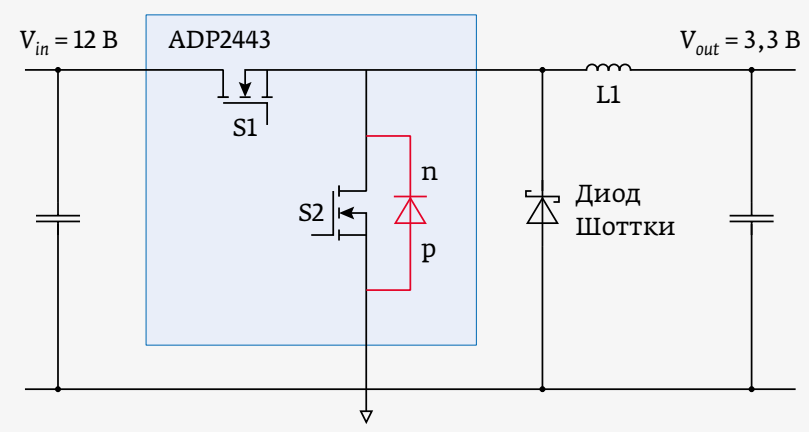

Рис. 2. Синхронный импульсный стабилизатор в схеме понижающего преобразователя с n-канальными MOSFET и дополнительным диодом Шоттки для минимизации помех

ADP2443 работает в диапазоне температур перехода от -40 до $125^{\circ} \mathrm{C}$, выпускается в 24-выводном корпуce LFCSP габаритами 4 × 4 мм.

Особенности ADP2443:

- непрерывный выходной ток: 3 A;

- входное напряжение: 4,5-36 В;

- интегрированные MOSFET верхнего и нижнего плеча: 98/35 мОм;

- опорное напряжение: 0,6 B $\pm 1 \%$;

- минимальное время включения: 50 нс;

- программируемая частота коммутации: 200 кГц - 1,8 МГц;

- синхронизация от внешнего тактового сигнала частотой 200 кГц - 1,8 МГц;

- вход разрешения с прецизионным порогом и выход "питание в норме";

- потактовое токоограничение с защитой от перегрузки по току путем кратковременного отключения;

- внешняя компенсация;

- программируемое время мягкого запуска;

- запуск при предварительно заряженном выходе;

- поддержка инструмента проектирования ADIsimPower.

Области применения:

- промежуточное преобразование напряжения питания;

- системы питания от многоэлементных батарей;

- промышленная автоматизация и управление технологическими процессами;

- медицина и здравоохранение;

- серверы и сетевые устройства. 